\title{
Serum Lipids and Lipoproteins in Children from Families with Early Coronary Heart Disease ${ }^{\star}$
}

\author{
I. TAMIR, Y. BOJANOWER, O. LEVTOW, D. HELDENBERG, Z. DICKERMAN, \\ and B. WERBIN \\ From the Metabolic Unit, Paediatric Department 'B', Hadassa Hospital, Tel Aviv Medical Centre, \\ Tel Aviv University Medical School, Tel Aviv, Israel
}

Tamir, I., Bojanower, Y., Levtow, O., Heldenberg, D., Dickerman, Z., and Werbin, B. (1972). Archives of Disease in Childhood, 47, 808. Serum lipids and lipoproteins in children from families with early coronary heart disease. Serum lipids and lipoproteins of 64 men under the age of 41 years who survived for more than 6 months after a myocardial infarction, and of their children were investigated. 26 fathers and all their 55 children had normal serum lipids and lipoprotein patterns. 38 fathers had normal serum lipid concentration and abnormal lipoprotein pattern; of these, 23 had hyper- $\beta$-lipoproteinaemia, 11 had increase in both $\beta$ - and pre- $\beta$-lipoprotein, and 4 had increase in pre- $\beta$-lipoprotein only. 30 of the 85 children whose fathers had abnormal lipoproteins were found to have type II hyperlipoproteinaemia regardless of the class of hyperlipaemia found in the father. The greatest incidence of lipoprotein abnormality was found in children of fathers of hyper- $\beta$-lipoproteinaemia.

It is now well established that individuals with certain forms of primary hyperlipoproteinaemia have an increased risk of developing coronary heart disease at an early age, and that the risk is greatest for those with familial hyper- $\beta$-lipoproteinaemia (Slack, 1969) (Type II hyperlipoproteinaemia in the classification of Fredrickson, Levy, and Less, 1967). If therapy designed to lower serum $\beta$-lipoprotein concentration is to be effective in preventing or delaying coronary heart disease in these patients, it is probably important to start treatment in childhood (Lloyd and Wolff, 1969).

Clinical manifestation of most of the primary hyperlipoproteinaemias, and particularly of the more common heterozygous form of familial hyper- $\beta$-lipoproteinaemia, rarely occurs during childhood, and the diagnosis is usually made by examination of the serum lipoproteins as part of a family study.

The importance of estimating serum lipids and lipoproteins in children with a strong family history of early coronary heart disease does not yet appear to have been evaluated by means of a

\footnotetext{
Received 6 March 1971.

^Presented at the XIIIth International Congress of Pediatrics, Vienna, 1971.
}

systematic study, and the purpose of the present investigation was to carry out such a study in children whose fathers had had a myocardial infarction before the age of 41 years.

\section{Patients and Methods}

Sixty-four men under the age of 41 years (mean 39, range 35-41) who were admitted to the Tel Aviv Medical Center with myocardial infarction and survived for more than 6 months form the basis of this study.

None was obese (weight in excess of $20 \%$ of standard weight for height) and none had clinical diabetes mellitus or a family history of diabetes mellitus in a first-degree relative. Serum lipids and lipoproteins were investigated in the patients, their wives, and children. The determinations on the patients were made at least 6 months after the infarction and none had had any medication during the preceding three months.

Venous blood was obtained after an overnight fast of at least $\mathbf{1 4}$ hours. In all families a dietary history was obtained to exclude major 'abnormalities' in food consumption. In four families it was found that the diet consumed provided more than $65 \%$ of calories from carbohydrates. These families were instructed to consume a 'normal' diet (carbohydrates provided about $50 \%$ of calories) for 2 weeks before the investigation.

Total serum cholesterol was estimated by the method of Rappaport and Eichhorn (1960), triglyceride by the method of Shafrir and Khassis (1969), and phospho- 
lipids by the method of Bartlett (1959). Paper electrophoresis of serum lipoproteins was carried out by the method of Salt and Wolff (1957).

\section{Results}

In all families the maternal serum lipids and lipoproteins were normal. The results in the fathers and the children are given in Tables $I$ and II. In the study, serum cholesterol concentration greater than $250 \mathrm{mg} / 100 \mathrm{ml}$ and triglyceride greater than $150 \mathrm{ml} / 100 \mathrm{ml}$ have been regarded as abnormal, these values being above the ranges found in healthy adult males and children from a similar population.

Twenty-six fathers (41\%) had normal serum lipids and lipoprotein patterns, 23 (36\%) had hyper- $\beta$-lipoproteinaemia with increased serum cholesterol and normal triglyceride, 11 (17\%) had increases in both $\beta$ - and pre- $\beta$-lipoproteins with increased serum cholesterol and triglyceride, and $4(6 \%)$ increased pre- $\beta$-lipoprotein only with increased serum triglyceride and normal cholesterol.

In the families in which the father had normal serum lipoproteins all 55 children were likewise normal. 20 of the 47 children whose fathers had increased $\beta$-lipoproteins had hyper- $\beta$-lipoproteinaemia. The remaining 27 had a normal pattern. 9 of the 30 children whose fathers had increased $\beta$ - and pre- $\beta$-lipoproteins had an abnormal pattern and in all cases this was hyper- $\beta$-lipoproteinaemia with increased serum cholesterol but normal triglyceride. Only 1 of the 8 children whose father had increased pre- $\beta$-lipoproteins was abnormal; again this child had hyper- $\beta$-lipoproteinaemia but no increase in pre- $\beta$-lipoprotein.

\section{Discussion}

In spite of advances in the identification and classification of hyperlipoproteinaemic disorders, problems still exist regarding the exact definition

TABLE I

Fasting Serum Lipids (mg/100 ml, mean and range) and Lipoprotein Pattern in 64 Male Survivors of Myocardial Infarction

\begin{tabular}{|c|c|c|c|c|}
\hline Lipoprotein Pattern & No. & TC & $\mathrm{Tg}$ & PL \\
\hline Normal & 26 & $\begin{array}{c}213 \\
171-249\end{array}$ & $\begin{array}{c}88 \\
62-139\end{array}$ & $\begin{array}{c}224 \\
144-281\end{array}$ \\
\hline Increased $\beta$-lipoprotein & 23 & $\begin{array}{c}307 \\
251-398\end{array}$ & $\begin{array}{c}87 \\
44-143\end{array}$ & $\begin{array}{c}267 \\
208-330\end{array}$ \\
\hline Increased $\beta$ - and pre- $\beta$-lipoprotein & 11 & $\begin{array}{c}306 \\
252-420\end{array}$ & $\begin{array}{c}199 \\
160-269\end{array}$ & $\begin{array}{c}291 \\
247-333\end{array}$ \\
\hline Increased pre- $\beta$-lipoprotein & 4 & $\begin{array}{c}225 \\
210-239\end{array}$ & $\begin{array}{c}215 \\
191-277\end{array}$ & $\begin{array}{c}241 \\
226-281\end{array}$ \\
\hline Control values (obtained in healthy adult men age $25-40$ years) & 25 & $\begin{array}{c}213 \\
189-245\end{array}$ & $\begin{array}{c}105 \\
60-147\end{array}$ & $\begin{array}{c}219 \\
195-293\end{array}$ \\
\hline
\end{tabular}

TABLE II

Fasting Lipids ( $\mathrm{mg} / 100 \mathrm{ml}$, mean and range) and Lipoprotein Pattern in 140 Children of Fathers with Early Myocardial Infarction

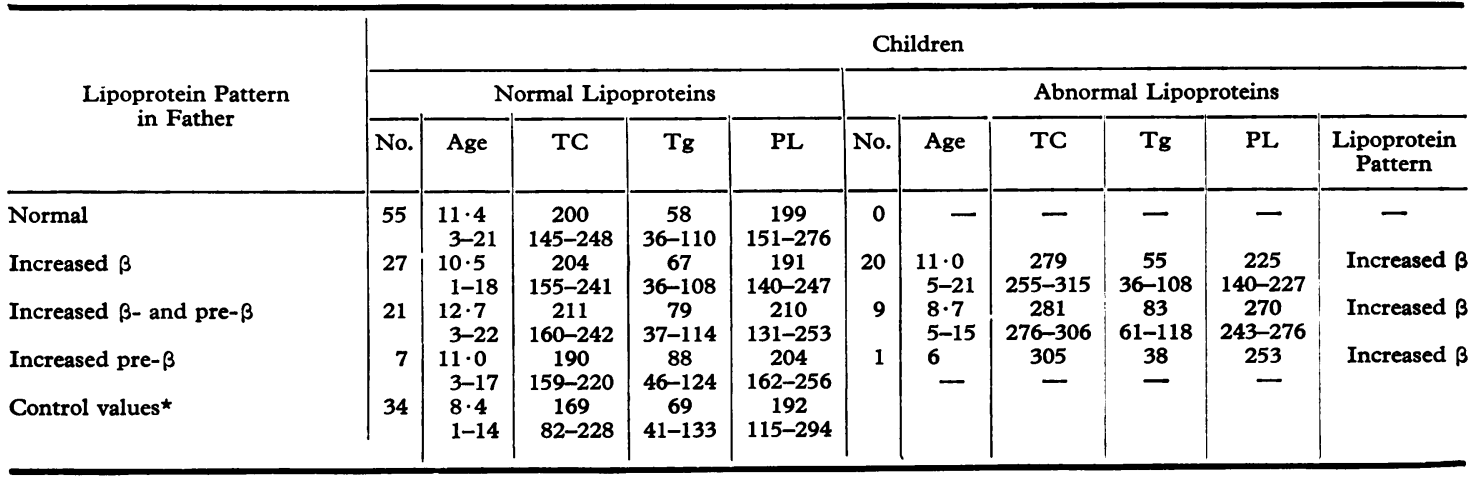

^Obtained from children in hospital without acute illness or metabolic disorders, or family history of myocardial infarction. 
of some of these states. Familial type II hyperlipoproteinaemia is probably best defined by an increased concentration of $\beta$-lipoprotein cholesterol in the serum, but even this determination (which requires preparative ultracentrifugation for the analysis) does not provide absolute discrimination between affected and nonaffected individuals (Fredrickson, 1971). In our study, in which ultracentrifugation was not carried out, it must be accepted that there may be some overlap between our 'normal' and affected groups. Furthermore, in those individuals in whom increased serum cholesterol was accompanied by increased serum triglyceride, electrophoretic separation did not show sufficiently obvious separation of $\beta$ - from pre- $\beta$-lipoprotein to exclude broad- $\beta$ disease (Type III) on this examination alone; again ultracentrifugal analysis would have been required. We think it likely, however, that most of these patients had Type IIb pattern of familial hyper- $\beta$ lipoproteinaemia recently described (Beaumont et al., 1970), and the fact that all the affected children of fathers with this pattern had hyper- $\beta$ lipoproteinaemia, and none had raised triglyceride level or a broadened $\beta$-band on electrophoresis, supports this view.

The incidence of hyperlipoproteinaemia (59\%) in young male survivors of coronary heart disease in our study is comparable with that reported by Heinle et al. (1969) who found hyperlipidaemia in $50 \%$ of patients with angina and angiographically proven coronary heart disease. Our finding that 23 of the 38 men with hyperlipoproteinaemia had unequivocal type II hyperlipoproteinaemia emphasizes the importance of this disorder in relation to premature coronary heart disease, and the incidence of the lipoprotein abnormality in their children is in agreement with an autosomal dominant type of inheritance. The overall incidence of hyper- $\beta$ lipoproteinaemia in the children in this study $(21 \%)$ indicates the importance of examining serum lipids and lipoproteins in families in which evidence of accelerated atherosclerosis is found in order to detect 'high-risk' individuals at an early age.

We thank Dr. June K. Lloyd, Institute of Child Health, London, for helpful advice and criticism.

\section{REFERENCES}

Bartlett, G. R. (1959). Phosphorus assay in column chromatography. fournal of Biological Chemistry, 234, 466.

Beaumont, J. L., Carlson, L. A., Cooper, G. R., Fejfar, Z., Fredrickson, D. S., and Strasser, T. (1970). Classification of hyperlipidaemias and hyperlipoproteinaemias. Bulletin of the World Health Organization, 43, 891.

Fredrickson, D. S. (1971). Mutants, hyperlipoproteinaemia, and coronary artery disease. British Medical fournal, 2, 187.

Fredrickson, D. S., Levy, R. I., and Less, R. S. (1967). Fat transport in lipoproteins-and integrated approach to mechanisms and disorders. New England fournal of Medicine, 276, 34 and 94.

Heinle, R. A., Levy, R. I., Fredrickson, D. S., and Gorlin, R. (1969). Lipid and carbohydrate abnormalities in patients with angiographically documented coronary artery disease. American Fournal of Cardiology, 24, 178.

Lloyd, J. K., and Wolff, O. H. (1969). A paediatric approach to the prevention of atherosclerosis. Fournal of Atherosclerosis Research, 10, 135.

Rappaport, F., and Eichhorn, F. (1960). Sulfosalicylic acid as a substitute for paratoluene sulfonic acid. A. In the estimation of cholesterol. B. In the diagnostic test for systemic lupus erythematosus. Clinica Chimica Acta, 5, 161.

Salt, H. B., and Wolff, O. H. (1957). The applications of serum lipoprotein electrophoresis in paediatric practice. Archives of Disease in Childhood, 32, 404.

Shafrir, E., and Khassis, S. (1969). Role of enhanced fat mobilization in liver triglyceride accumulation in carbon tetrachlorideinduced liver injury. Israel fournal of Medical Sciences, 5, 975.

Slack, J. (1969). Risks of ischaemic heart-disease in familial hyperlipoproteinaemic states. Lancet, 2, 1380.

Correspondence to Dr. I. Tamir, Paediatric Department, 'Hadassa' Hospital, Balfour Street, Tel Aviv, Israel. 